\title{
Global Relapse in Blood
}

National Cancer Institute

\section{Source}

National Cancer Institute. Global Relapse in Blood. NCI Thesaurus. Code C159976.

Increase of neoplastic blood lymphocytes to B1 or greater in those with complete response. 